\title{
Mobility therapy and central or peripheral catheter-related adverse events in an ICU in Brazil*
}

\author{
Realização de fisioterapia motora e ocorrência de eventos adversos \\ relacionados a cateteres centrais e periféricos em uma UTI brasileira \\ Natália Pontes Lima, Gregório Marques Cardim da Silva, \\ Marcelo Park, Ruy Camargo Pires-Neto
}

\begin{abstract}
Objective: To determine whether mobility therapy is associated with central or peripheral catheter-related adverse events in critically ill patients in an ICU in Brazil. Methods: A retrospective analysis of the daily medical records of patients admitted to the Clinical Emergency ICU of the University of São Paulo School of Medicine Hospital das Clínicas Central Institute between December of 2009 and April of 2011. In addition to the demographic and clinical characteristics of the patients, we collected data related to central venous catheters (CVCs), hemodialysis (HD) catheters and indwelling arterial catheters (IACs): insertion site; number of catheter days; and types of adverse events. We also characterized the mobility therapy provided. Results: Among the 275 patients evaluated, CVCs were used in 49\%, HD catheters were used in 26\%, and 1ACs were used in 29\%. A total of 1,268 mobility therapy sessions were provided to patients while they had a catheter in place. Catheterrelated adverse events occurred in 20 patients (a total of 22 adverse events): 32\%, infection; 32\%, obstruction; and 32\%, accidental dislodgement. We found that mobility therapy was not significantly associated with any catheter-related adverse event, regardless of the type of catheter employed: $\mathrm{CVC}-\mathrm{OR}=0.8 ; 95 \% \mathrm{Cl}$ : 0.7-1.0; $\mathrm{p}=0.14 ; \mathrm{HD}$ catheter-OR $=1.04 ; 95 \% \mathrm{Cl}: 0.89-1.21 ; \mathrm{p}=0.56 ;$ or $\mathrm{IAC}-\mathrm{OR}=1.74 ; 95 \% \mathrm{Cl}: 0.94-3.23 ; \mathrm{p}=$ 0.07. Conclusions: In critically ill patients, mobility therapy is not associated with the incidence of adverse events involving CVCs, HD catheters, or IACs.
\end{abstract}

Keywords: Physical therapy modalities; Intensive care units; Catheters; Early ambulation.

\section{Introduction}

Early rehabilitation in intensive care unit (ICU) patients helps to prevent and minimize the deleterious effects of immobility, to improve functional capacity, and to reduce the duration of mechanical ventilation and length of hospital stay, as well as improving the quality of life of such patients. ${ }^{(1-4)}$ However, the literature describes some barriers that limit or preclude this rehabilitation. Some examples are disease severity, level of sedation, use of vasoactive drugs, and presence of catheters, whether central or peripheral. $^{(5,6)}$

The use of central or peripheral catheters for drug administration and monitoring in critically ill patients is common. In patients with difficult access, with multiple access sites, or with a bleeding disorder, partial or total confinement to bed to prevent catheter dislodgement or loss is still common. In addition, there is the concern about maintaining blood flow in patients undergoing continuous renal replacement therapy. ${ }^{(7)}$

Recent studies have shown that mobilization of patients with catheters is safe and is not associated with access-related or catheter-related adverse events. ${ }^{(6,8,9)}$ However, some centers still consider the presence of catheters a barrier to mobilization, delaying the start of rehabilitation..$^{(5,10)}$

1. Physical Therapist. Department of Physical Therapy, Hospital das Clínicas Central Institute, University of São Paulo School of Medicine, São Paulo, Brazil.

2. Physician. Intensive Care Unit, Department of Clinical Emergencies, University of São Paulo School of Medicine Hospital das 3. Clínicas Central Institute, São Paulo, Brazil.

Physical Therapist. Department of Pathology, University of São Paulo School of Medicine Hospital das Clínicas, São Paulo, Brazil. *Study carried out at the Hospital das Clínicas Central Institute, University of São Paulo School of Medicine, São Paulo, Brazil. Correspondence to: Natália Pontes Lima. Faculdade de Medicina, USP, Avenida Dr. Arnaldo, 455, sala 1155, CEP 01246-903, São Paulo, SP, Brasil.

Tel. 5511 2266-6470. E-mail: nataliaponteslima@yahoo.com.br

Financial support: None.

Submitted: 9 June 2014. Accepted, after review: 10 February 2015. 
Given that the literature on this topic is controversial and that most studies were conducted in centers in the United States and Australia, all of which provide physical therapy that is different from that provided in Brazil, the objective of the present study is to determine whether mobility therapy is associated with central or peripheral catheter-related adverse events in critically ill patients in an ICU in Brazil. Our hypothesis is that there is no association between mobility therapy and central or peripheral catheter-related adverse events such as accidental dislodgement or removal and infection.

\section{Methods}

This study was approved by the Human Research Ethics Committee of the Faculdade de Medicina da Universidade de São Paulo (FMUSP, University of São Paulo School of Medicine).

We performed a retrospective analysis of the daily medical and physical therapy records of patients admitted to the 6-bed ICU of the Department of Clinical Emergencies of the FMUSP Instituto Central do Hospital das Clínicas (ICHC, Hospital das Clínicas Central Institute) between December of 2009 and April of 2011. The daily record forms were developed prior to the study, were completed electronically, and had been in use for at least one year in the 1CU. Therefore, data on all study variables were available through an electronic medical records system.

Physical therapy in the ICU was characterized by respiratory therapy and by mobility therapy. In brief, respiratory therapy was based on airway clearance maneuvers (including aspiration), lung expansion techniques, adjustment of oxygen therapy, and inhalation therapy (the last of these being administered as medically prescribed). In addition, if the patient was mechanically ventilated, the physical therapist also assisted in adjustment of ventilator settings and in patient extubation. Mobility therapy consisted of upper limb, lower limb, and trunk exercises, in passive, active, and resistive modes. Exercise was performed with the patient lying on the bed, sitting on the bed, or sitting in an armchair, depending on the ability of the patient and at the discretion of the physical therapist. In addition, exercise in the standing position and ambulation around the bed and in the hallway was recommended.

The ICU multidisciplinary team comprised 1:6 nurse/patient, 1:2 nursing technician/patient,
$1: 6$ resident in physical therapy/patient, and 1:10 senior physical therapist/patient. Physical therapy was available 12 hours a day (from 7:00 a.m. to 7:00 p.m.), and, during that period, each patient usually received two visits, which were tailored to the needs of each individual.

Data collection included demographic characteristics and clinical data, such as age, gender, clinical admission diagnosis, Simplified Acute Physiology Score (SAPS) 3, site of admission, duration of mechanical ventilation, length of ICU stay, and mortality. In addition, we collected data related to central venous catheters (CVCs), hemodialysis (HD) catheters, and indwelling arterial catheters (IACs): insertion site; number of catheter days; and number of mobility therapy sessions conducted with a catheter in situ. The catheter-related adverse events considered were obstruction, accidental dislodgement or removal, and infection. The data we collected on mobility therapy included the frequency and level of each activity (in-bed exercise, sitting on the edge of the bed or out of bed, standing, and walking). All data were entered into tables and were checked by two researchers.

Statistical analysis was performed with Statistical Package for the Social Sciences, version 15.0 (SPSS Inc., Chicago, IL, USA). Descriptive analysis was performed using frequency of each event (percentage), mean (SD), or median (interquartile range [1QR]), when appropriate. For each catheter type (CVC, HD catheter, and $\mathrm{IAC})$, we determined the number of patients who experienced a catheter-related adverse event and the number of those who did not. Therefore, the patients were divided into two groups on the basis of presence or absence of catheter-related adverse events. We used the nonparametric MannWhitney test to compare the adverse event and non-adverse event groups in terms of number of catheter days and number of mobility therapy sessions, for each catheter type. Logistic regression analysis (including ORs and their 95\% Cls) was performed to determine the association between adverse events and number of mobility therapy sessions. The association analysis was adjusted for number of catheter days (confounding variable). For statistical analysis, the level of significance was set at $5 \%(p<0.05)$. 


\section{Results}

During the study period, 275 patients were admitted to the Clinical Emergency ICU of the ICHC-FMUSP, all of whom were included in the analysis. Patient demographic characteristics and clinical data are shown in Table 1. The mean age of the patients was $48 \pm 18$ years, and most patients (84\%) were admitted for clinical decompensation. The remaining 16\% were admitted for surgical reasons (postoperative period). In addition, of the 275 patients, 82 (30\%) were admitted with a diagnosis of sepsis. The major source of origin was the emergency room (in $53 \%$ ), followed by the ward because of clinical worsening (in 26\%). The length of ICU stay was 5 [1QR: 7] days, and 44\% of the patients required invasive mechanical ventilation during that period. Overall ICU mortality was $17 \%$.

Of the 275 patients, $82 \%(n=225)$ received at least one mobility therapy session (a total of 2,638 sessions) and 94\% $(n=258)$ received at least one respiratory therapy session throughout their ICU stay. In addition, of those 275 patients, $31 \%(n=86)$ sat in an armchair (i.e., out of bed) and $29 \%(n=80)$ walked at least once during their ICU stay. Patients with orotracheal tubes (orotracheal intubation) or tracheostomy tubes (with or without mechanical ventilation) underwent a total of 1,428 mobility therapy sessions, in which the main activity was ambulation, in 237

Table 1 - Patient demographic characteristics. ${ }^{\text {a }}$

\begin{tabular}{|c|c|}
\hline Variable & $(n=275)$ \\
\hline Age, years & $48 \pm 18$ \\
\hline Male gender, $\mathrm{n}(\%)$ & $135(49)$ \\
\hline SAPS3 & $38 \pm 19$ \\
\hline \multicolumn{2}{|l|}{ Diagnosis, n (\%) } \\
\hline Clinical & $229(84)$ \\
\hline Surgical & $45(16)$ \\
\hline \multicolumn{2}{|l|}{ Site of admission, $n(\%)^{b}$} \\
\hline Emergency room & $145(53)$ \\
\hline Ward (clinical worsening) & $72(26)$ \\
\hline Operating room (PO) & $45(16)$ \\
\hline Others & $12(4)$ \\
\hline Mechanically ventilated patients, $\mathrm{n}(\%)$ & $122(44)$ \\
\hline Duration of mechanical ventilation, days ${ }^{c}$ & $3[4]$ \\
\hline Length of ICU stay, days ${ }^{c}$ & $5[7]$ \\
\hline Mortality, n (\%) & $47(17)$ \\
\hline \multicolumn{2}{|c|}{$\begin{array}{l}\text { SAPS: Simplified Acute Physiology Score; and PO: } \\
\text { postoperative period. avalues expressed as mean } \pm \text { SD, } \\
\text { except where otherwise indicated. bInformation unavailable } \\
\text { for four patients. 'Values expressed as median [interquartile } \\
\text { range]. }\end{array}$} \\
\hline
\end{tabular}

sessions; orthostasis, in 161 sessions; sitting in an armchair, in 91 sessions; sitting on the edge of the bed, in 60 sessions; and in-bed exercise, in 879 sessions. During those sessions, there were no reports of self-extubation or accidental extubation.

Table 2 shows the frequency of patients who experienced catheter-related adverse events by catheter type, as well as the number of catheter days, the frequency of mobility therapy sessions conducted with a catheter in situ, and the most successfully accomplished activity in those sessions, by catheter type and by absence or presence of catheter-related adverse events. Among the 275 patients evaluated, CVCs were used in 49\%, HD catheters were used in $26 \%$, and IACs were used in $29 \%$. In addition, 86 patients (31\%) required different types of catheters simultaneously. The main insertion sites were the jugular and subclavian veins, for CVCs and HD catheters, and the radial artery, for IACs. A total of 1,268 mobility therapy sessions were conducted with a catheter in situ, and the most prevalent activity was in-bed limb mobilization (in passive, active, and resistive modes). Catheter-related adverse events occurred in 20 patients, and, in two of those 20 patients, there were two adverse events (a total of 22 catheter-related adverse events). The adverse events were as follows: infection ( $n=5$, CVC; $n=2$, HD catheter); obstruction $(n=5, H D$ catheter; $n=2,1 A C)$; and accidental dislodgement or removal ( $n=4$, CVC; $n=1$, HD catheter; $n=2,1 \mathrm{AC}$ ). In one case, the cause of the adverse event was not recorded on the chart.

When comparing the adverse event and non-adverse event groups by catheter type, we found that the number of catheter days was greater in the former than in the latter-(median [1QR]) 8 [10] vs. 5 [4] days for CVCs $(p<0.05)$; and 7 [15] vs. 3 [4] days for IACs ( $p<0.05)$-as was the number of mobility therapy sessions per patient-(median [1QR]) 12 [19] vs. 4 [9] for HD catheters $(p<0.05)$. Logistic regression analysis for each catheter type, adjusted for number of catheter days, revealed that mobility therapy was not significantly associated with any catheterrelated adverse event, regardless of the type of catheter employed: $\mathrm{CVC}-\mathrm{OR}=0.862 ; 95 \% \mathrm{Cl}$ : 0.7-1.05; $p=0.146$; HD catheter $-0 R=1.046$; $95 \% \mathrm{Cl}: 0.898-1.219 ; \mathrm{p}=0.562$; or $\mathrm{IAC}-\mathrm{OR}=$ 1.746; $95 \% \mathrm{Cl}: 0.942-3.237 ; \mathrm{p}=0.077$. 
Table 2 - Characteristics of the catheters used and of the mobility therapy provided.

\begin{tabular}{|c|c|c|c|c|c|c|}
\hline \multirow[t]{3}{*}{ Variable } & \multicolumn{2}{|c|}{ CVC } & \multicolumn{2}{|c|}{ HD catheter } & \multicolumn{2}{|c|}{ IAC } \\
\hline & \multicolumn{2}{|c|}{ Adverse event } & \multicolumn{2}{|c|}{ Adverse event } & \multicolumn{2}{|c|}{ Adverse event } \\
\hline & Absent & Present & Absent & Present & Absent & Present \\
\hline Patients, n (\%) & $126(94)$ & $8(6)$ & $63(89)$ & $8(11)$ & $75(95)$ & $4(5)$ \\
\hline Catheter days, median [1QR] & $5[4]$ & $8[10]^{*}$ & $6[7]$ & $9[16]$ & $3[4]$ & $7[15]^{*}$ \\
\hline Mobility therapy sessions (n), median $[1 Q R]^{a}$ & $4[5]$ & $6[13]$ & $4[9]$ & $12[19]^{*}$ & $2[3]$ & $10[22]$ \\
\hline \multicolumn{7}{|l|}{ Main insertion site s,c $^{b}$} \\
\hline Jugular vein, $\mathrm{n}$ & 85 & 5 & 34 & 5 & - & - \\
\hline Subclavian vein, $\mathrm{n}$ & 33 & 3 & 11 & 1 & - & - \\
\hline Femoral vein, $\mathrm{n}$ & 6 & 1 & 17 & 2 & - & - \\
\hline Radial artery, $\mathrm{n}$ & - & - & - & & 50 & 3 \\
\hline Dorsalis pedis artery, $n$ & - & - & - & - & 15 & 0 \\
\hline Femoral artery, n & - & - & - & - & 3 & 1 \\
\hline \multicolumn{7}{|l|}{ Most successfully accomplished activity } \\
\hline Ambulation, $\mathrm{n}$ & 23 & 2 & 125 & 0 & 3 & 0 \\
\hline Orthostasis, $\mathrm{n}$ & 51 & 3 & 101 & 2 & 5 & 0 \\
\hline Sitting in an armchair, $\mathrm{n}$ & 25 & 3 & 38 & 3 & 7 & 0 \\
\hline Sitting on the edge of the bed, $n$ & 36 & 2 & 39 & 8 & 5 & 1 \\
\hline Limb mobilization, $\mathrm{n}$ & 533 & 42 & 382 & 59 & 227 & 20 \\
\hline
\end{tabular}

CVC: central venous catheter; HD: hemodialysis; IAC: indwelling arterial catheter; and IQR: interquartile range. ${ }^{a}$ Mobility therapy sessions received by each patient with a catheter in situ. ${ }^{\text {b}}$ There can be more than one insertion site in each individual patient. 'The insertion site was not described on the chart in 3\% (CVC); 4\% (HD catheter), and 9\% (IAC) of the cases. ${ }^{*} p<0.05$ when compared with the respective non-adverse event group.

\section{Discussion}

In the present study, we found that, of the 275 patients admitted to the Clinical Emergency ICU of the ICHC-FMUSP, $82 \%$ received mobility therapy, whereas $94 \%$ received respiratory therapy. Of a total of 2,638 mobility therapy sessions, 1,268 were provided to patients while they had a catheter in place (CVC, IAC, or HD catheter), and we found that mobility therapy was not significantly associated with any catheter-related adverse event, regardless of the type of catheter employed. In addition, in 1,428 sessions provided during orotracheal intubation or during the use of a tracheostomy tube (with or without mechanical ventilation), there were no reported episodes of self-extubation or accidental extubation.

Recent cohort or prevalence studies have found that 34 to $62 \%$ of ICU patients receive mobility therapy. ${ }^{(9,11,12)} \ln$ our study, $82 \%$ of the patients received at least one mobility therapy session. This difference in the proportion of treated patients can be explained by the large number of physical therapists in our ICU (1:10 senior physical therapist/patient and 1:6 resident in physical therapy/patient), unlike what occurs in ICUs in other countries, in which there is a strong presence of respiratory therapists. ${ }^{(13)}$
However, the large number of physical therapists did not imply treatment aimed at more complex levels of mobilization, the most prevalent activity being in-bed exercise. One explanation for this finding is that early mobilization in ICUs in Brazil remains unusual, despite the constant, daily presence of the physical therapist. Another factor that can explain this situation is that only the activities conducted with a catheter in situ were analyzed, and patients with CVCs and IACs usually experience increased hemodynamic instability and increased disease severity.

In our study, we found no association between catheter-related adverse events and mobilization (mobility therapy) in the ICU. In addition, the incidence of catheter-related adverse events was $2 \%$ in our study (22 events in 1,268 sessions), being similar to the less than $5 \%$ incidence reported in other centers. ${ }^{(1,2,14-18)}$ Damluji et al., ${ }^{(6)}$ when evaluating 101 patients who underwent 253 physical therapy sessions with a femoral catheter in situ, found that exercise was not associated with catheter-related adverse events. Perme et al., ${ }^{(8)}$ when evaluating 77 patients with 92 femoral catheters (50 1ACs, 15 CVCs, and $27 \mathrm{HD}$ catheters), found that exercise was not associated with catheter-related thrombotic or obstructive complications. Likewise, we found 
no association between mobility therapy and catheter-related adverse events. However, unlike in the aforementioned studies, we assessed not only the femoral site but also the jugular and subclavian sites, for CVCs and HD catheters, and the radial and dorsalis pedis arteries, for IACs. In fact, the most common catheter insertion sites were the radial and jugular sites, given that catheter insertion into the femoral site is not the primary option in our ICU (Table 2). Therefore, even when different insertion sites were used, exercise did not imply an increase in the number of catheter-related adverse events.

The present study has some limitations. First, this was a single-center study-direct comparison with other hospitals in Brazil should be conducted with caution. However, our findings are similar to those of studies conducted in countries where the difference in care is greater than that observed among hospitals in Brazil. Second, the study has a retrospective design-data were retrieved from a database and from patient charts. Therefore, we can establish only an association, not a causeand-effect relationship. In addition, information on catheter insertion site could not be obtained for all cases-that is, for 3\% (CVC), 4\% (HD catheter), and 9\% (IAC)-nor was it possible to obtain information on one CVC-related adverse event. However, we believe that these factors do not alter the results of this study, because catheter insertion site was not used for analysis, being of descriptive value only. Third, the only factors used in our analysis were mobility therapy and number of catheter days. Thus, it was not possible to determine the effect of medical and nursing procedures (e.g., hygiene, transport, and tube passage) on our results. Catheter infection is known to be caused by multiple factors and can result from patient handling by healthcare workers. For this reason, the reported prevalence, which refers specifically to mobility therapy, might be overestimated relative to reality.

On the basis of the present study, we conclude that, in the study population, mobility therapy is not associated with the incidence of adverse events involving CVCs, HD catheters, or IACs.

\section{References}

1. Schweickert WD, Pohlman MC, Pohlman AS, Nigos C, Pawlik AJ, Esbrook CL, et al. Early physical and occupational therapy in mechanically ventilated, critically ill patients: a randomised controlled trial. Lancet. 2009;373(9678):187482. http://dx.doi.org/10.1016/S0140-6736(09)60658-9
2. Morris PE, Goad A, Thompson C, Taylor K, Harry B, Passmore L, et al. Early intensive care unit mobility therapy in the treatment of acute respiratory failure. Crit Care Med. 2008;36(8):2238-43. http://dx.doi.org/10.1097/ CCM.0b013e318180b90e

3. Stiller K. Physiotherapy in intensive care: an updated systematic review. Chest. 2013;144(3):825-47. http:// dx.doi.org/10.1378/chest.12-2930

4. Kayambu G, Boots R, Paratz J. Physical therapy for the critically ill in the ICU: a systematic review and metaanalysis. Crit Care Med. 2013;41(6):1543-54. http:// dx.doi.org/10.1097/CCM.0b013e31827ca637

5. Leditschke 1A, Green M, Irvine J, Bissett B, Mitchell IA. What are the barriers to mobilizing intensive care patients? Cardiopulm Phys Ther J. 2012;23(1):26-9.

6. Damluji A, Zanni JM, Mantheiy E, Colantuoni E, Kho ME, Needham DM. Safety and feasibility of femoral catheters during physical rehabilitation in the intensive care unit. J Crit Care. 2013;28(4):535.e9-15.

7. Morris PE. Moving our critically ill patients: mobility barriers and benefits. Crit Care Clin. 2007;23(1):1-20. http://dx.doi.org/10.1016/j.ccc.2006.11.003

8. Perme C, Lettvin C, Throckmorton TA, Mitchell K, Masud F. Early Mobility and Walking for Patients with Femoral Arterial Catheters in Intensive Care Unit : a Case Series. JACPT. 2011;2(1):32-6. http://dx.doi. org/10.1097/01592394-201102010-00004

9. Nydahl P, Ruhl AP, Bartoszek G, Dubb R, Filipovic S, Flohr HJ, et al. Early mobilization of mechanically ventilated patients: a 1-day point-prevalence study in Germany. Crit Care Med. 2014;42(5):1178-86. http:// dx.doi.org/10.1097/CCM.0000000000000149

10. Berney SC, Harrold M, Webb SA, Seppelt 1, Patman S, Thomas PJ, et al. Intensive care unit mobility practices in Australia and New Zealand: a point prevalence study. Crit Care Resusc. 2013;15(4):260-5.

11. Mendez-Tellez PA, Dinglas VD, Colantuoni E, Ciesla N, Sevransky JE, Shanholtz C, et al. Factors associated with timing of initiation of physical therapy in patients with acute lung injury. J Crit Care. 2013;28(6):980-4. http://dx.doi.org/10.1016/j.jcrc.2013.06.001

12. Sricharoenchai T, Parker AM, Zanni JM, Nelliot A, Dinglas VD, Needham DM. Safety of physical therapy interventions in critically ill patients: a single-center prospective evaluation of 1110 intensive care unit admissions. J Crit Care. 2014;29(3):395-400. http:// dx.doi.org/10.1016/j.jcrc.2013.12.012

13. Hodgin KE, Nordon-Craft A, McFann KK, Mealer ML, Moss M. Physical therapy utilization in intensive care units: results from a national survey. Crit Care Med. 2009;37(2):561-6; quiz 566-8 . http://dx.doi.org/10.1097/ CCM.0b013e3181957449

14. Needham DM, Korupolu R, Zanni JM, Pradhan P, Colantuoni E, Palmer JB, et al. Early physical medicine and rehabilitation for patients with acute respiratory failure: a quality improvement project. Arch Phys Med Rehabil. 2010;91(4):536-42. http://dx.doi.org/10.1016/j. apmr.2010.01.002

15. Bourdin G, Barbier J, Burle JF, Durante G, Passant S, Vincent B, et al. The feasibility of early physical activity in intensive care unit patients: a prospective observational one-center study. Respir Care. 2010;55(4):400-7.

16. Pohlman MC, Schweickert WD, Pohlman AS, Nigos C, Pawlik AJ, Esbrook CL, et al. Feasibility of physical 
and occupational therapy beginning from initiation of mechanical ventilation. Crit Care Med. 2010;38(11):208994. http://dx.doi.org/10.1097/CCM.0b013e3181f270c3 17. Clark DE, Lowman JD, Griffin RL, Matthews HM, Reiff DA. Effectiveness of an early mobilization protocol in a trauma and burns intensive care unit: a retrospective cohort study. Phys Ther. 2013;93(2):186-96. http:// dx.doi.org/10.2522/ptj.20110417

18. Zanni JM, Korupolu R, Fan E, Pradhan P, Janjua K, Palmer JB, et al. Rehabilitation therapy and outcomes in acute respiratory failure: an observational pilot project. J Crit Care. 2010;25(2):254-62. http://dx.doi.org/10.1016/j.jcrc.2009.10.010 